\title{
An Experimental Evaluation of the Weathering Effects on Mine Shaft Lining Materials
}

\author{
W. Yang, ${ }^{1,2}$ A. M. Marshall, ${ }^{2}$ D. Wanatowski, ${ }^{3}$ and L. R. Stace ${ }^{2}$ \\ ${ }^{1}$ Key Laboratory of Transportation Tunnel Engineering, Ministry of Education, First North Section 111, Erhuan Road, \\ Chengdu 610031, China \\ ${ }^{2}$ University of Nottingham, University Park, Nottingham NG7 2RD, UK \\ ${ }^{3}$ Southwest Jiaotong University-Leeds Joint School, Xipu Campus, Chengdu 611756, China
}

Correspondence should be addressed to W. Yang; yangwenboll79@hotmail.com

Received 10 August 2016; Accepted 1 December 2016; Published 3 January 2017

Academic Editor: Luigi Nicolais

Copyright (C) 2017 W. Yang et al. This is an open access article distributed under the Creative Commons Attribution License, which permits unrestricted use, distribution, and reproduction in any medium, provided the original work is properly cited.

\begin{abstract}
Many shaft collapses are related to the deterioration and failure of the masonry shaft lining materials. In modern mine shaft, concrete is widely used to provide support. To analyse shafts stability, the properties of the lining need to be well defined. The behaviour of masonry and concrete can be considerably affected by long-term exposure to harsh mine water. This paper presents a study which focuses on the weathering effects of mine water on lining materials (brick, mortar, and concrete). To reproduce the weathering process, samples were placed into solutions of potable water, artificial mine water, and a more aggressive mine-water solution for just less than one year. Four phases of laboratory tests were conducted throughout the time period to assess the degradation of mechanical properties of the lining materials. Particular attention is given to the degradation of material strength and stiffness. Results indicate that the harsh acidic mine water has pronounced detrimental effects on the strength and stiffness of mortar. The weathering process is shown to have the most significant effect on the stiffness of concrete and mortar. It is also shown that the use of mass loss as an index for evaluation of mechanical properties may not be appropriate.
\end{abstract}

\section{Introduction}

Mine shafts allow movement of materials and personnel from surface to subsurface locations and are integral components of effective mine operations. The stability of a shaft, especially within the superficial soil layer near the ground surface, relies heavily on the shaft lining. During the operational life of a mine, shaft stability is essential in order to ensure economic viability of mining operations and to safeguard against injury and loss of life. Consequently, considerable effort is devoted to maintain the integrity of the shaft while the mine is active. Once mining activities cease, however, there is little financial incentive for maintaining shaft stability, and measures that have been adopted to provide long-term support to shafts have tended to be minimal and often proven to be inadequate. There is considerable variability in the nature of treatment works undertaken to ensure shaft stability in the long term. These include partial or complete infilling of the shaft using materials which may not be ideally suited for the intended purpose (usually left-over spoil found on-site), and capping systems built from wood which, with the passage of time, pose an increasing threat of sudden failure due to material degradation. In many cases, the shaft lining is the only structure left in place to support the surrounding soil. As the structural integrity of the lining decreases over time, the stability of the shaft structure can reach a critical state nearing collapse.

In UK, there are over 100,000 recorded mine shafts, with many more unrecorded shafts in existence [1]. The exact location of the shafts, as well as the details and structural integrity of their linings, is a topic of considerable uncertainty. The condition of the shaft lining materials inevitably deteriorates over time, a feature which can be accelerated if the lining is submersed within harsh acidic water often found in abandoned coal mines. There have been many recorded incidents of mine shaft collapse in Europe, some undoubtedly due to the loss of support resulting from shaft lining deterioration [2]. 
Analysis of mine shaft stability relies on a good estimation of the material properties of the lining and the surrounding soil/rock, as well as an understanding of the interactions that occur between the shaft and the surrounding materials. A variety of research has been done to study the behaviour of shaft linings. Simple analytical methods for analysing mine shafts provide an efficient method for assessing stability. For example, Rama Mohana Rao [3] presented a study of the limit state method and developed an analytical formula for calculation of lining thickness and limiting depths of shafts for adoption of structural concrete as a lining material. Numerical modelling can capture more of the complex material behaviour and problem geometries than simple analytical tools, as well as the soil/rock-shaft interactions that take place, most notably due to local mining activities. For example, Jia et al. [4] presented a numerical study of deep mine and identified the cause and mechanisms of failure of the shaft linings in the affected zone. Mendez et al. [5] developed a numerical model to examine the effect of the shaft lining-soil interaction on shaft pressures and concluded that neglecting the interaction between the shaft and soil, as assumed by most continuum models, leads to higher values of horizontal pressure. Yu et al. [6] studied the influence of coal extraction on the stability of shaft linings and showed that mining too close to a shaft can have significant effects on the lining stresses.

An understanding of the mechanical properties of the shaft lining material is essential for any stability analysis. Use of design material properties is suitable for consideration of the shaft in the short term; however, the long-term evaluation of shaft stability is also important. There has been relatively little work done to study the deterioration of the mechanical properties of shaft lining materials over time within harsh mine shaft environments.

The majority of historic mine shafts are supported by masonry structures, typically using stone blocks and brickwork. This form of construction is no longer routinely used and concrete linings are generally preferred. The lining material of masonry and concrete can be significantly weathered due to factors such as water, climatic changes, salt, and acid attack. A variety of research has been conducted to understand the weathering process on brick, mortar, and concrete. These materials can be affected by soluble salts (e.g., [7-9]), sodium sulfate expansion ([10]), atmospheric corrosion from $\mathrm{SO}_{2}, \mathrm{NO}_{2}$, and $\mathrm{O}_{3}$ (e.g., $[11,12]$ ), carbonation (in concrete, e.g., $[13,14]$ ), and sulfuric acid (e.g., $[15,16]$ ). Most of the research described above used visual inspection and mass loss to determine the degree of weathering on the materials. Only limited data of degradation of mechanical properties of brickwork and concrete due to weathering is reported (e.g., the brick/mortar interface strength and stiffness data reported by Gentilini et al. [9]).

The focus of this paper is the study of the degradation of the mechanical properties of shaft lining materials (brick, mortar, and concrete). The data presented provides some quantitative measurements of the deterioration of shaft materials' strength and stiffness over time when subjected to a variety of weathering environments. The data is useful for input in long-term shaft stability calculations and numerical models.
The paper is divided into three main sections. Section 2 presents details of the experimental programme undertaken while Section 3 discusses the results obtained from the tests. Finally, Section 4 presents the conclusions from the study.

\section{Materials and Test Methodology}

2.1. Test Materials. The aim of this study was to determine harsh mine water and time effects on shaft lining materials. Brick, mortar, and concrete were tested. The bricks used were Mellowed Red Sovereign Stock supplied by Wienerberger Ltd., UK [18]. The mortar samples were prepared based on BS PD 6678 [19]. The compressive strength class of the mortar was M6 and the cement/sand ratio was 155/710 (by mass). For the concrete samples, the aggregate-sand-cement-water ratio was 3.63-3.33-1-0.74 (by mass). The 7-day compressive strength of the concrete was reported as $21.5 \mathrm{~N} / \mathrm{mm}^{2}$. The cement used to prepare the mortar and concrete samples was Rugby High Strength Portland Cement [20]. The mortar and concrete were cast as cubes and cured for 28 days and then cored into cylinders for laboratory testing. The diameter and height of the cylinders were $37 \mathrm{~mm}$ and $74 \mathrm{~mm}$, respectively. Cylinders of brick were also prepared for the same specifications. An example of the test specimens is shown in Figure 1.

2.2. Test Methods. In order to replicate the environmental conditions that cause degradation of shaft lining materials, a number of samples were immersed for just less than one year in one of three prepared solutions: potable water, a representative mine water, and a more aggressive version of the mine water. Laboratory tests were performed at different time intervals to evaluate the weathering effects on the mechanical parameters of the test materials. The aggressive solution was used to model some extreme cases [21] and to accelerate the weathering process in order to gain insight into the longer-term weathered conditions of the materials. Four phases of laboratory tests were conducted during the time. Phase 0 tested the initial material properties of the samples. The degradation of the structural parameters of the test materials was evaluated at approximately 16-week intervals by calculating the mass loss of the samples and measuring the compressive and shear strength by uniaxial and triaxial tests.

2.2.1. Immersion. The expected $\mathrm{pH}$ and concentration of the main chemical components of the mine water and aggressive solutions are shown in Table 1 . The properties of the mine water were based on data obtained from a previous research project funded by the Research Fund for Coal and Steel (RFCS): PREdiction and Monitoring of SubSIDENCE Hazards above Coal Mines (PRESIDENCE) [17]. In order to keep the $\mathrm{pH}$ and concentration of the solutions as constant as possible, all the solutions were refreshed every 3 weeks during the duration of the immersion process. The $\mathrm{pH}$ of the mine water and the aggressive solution was monitored during the tests by a $\mathrm{pH}$ meter. Water pumps were used to circulate the water to ensure uniform distribution of the chemicals in the solutions.

2.2.2. Laboratory Testing. Four phases of laboratory tests were performed throughout the weathering process (Phase 0 
TABLE 1: Concentration of the main chemical components for the immersion baths.

\begin{tabular}{|c|c|c|c|c|c|}
\hline & $\mathrm{Mg}(\mathrm{mg} / \mathrm{L})$ & $\mathrm{Na}(\mathrm{mg} / \mathrm{L})$ & $\mathrm{Cl}(\mathrm{mg} / \mathrm{L})$ & $\mathrm{SO}_{4}(\mathrm{mg} / \mathrm{L})$ & $\mathrm{pH}$ \\
\hline Mine water (measured [17]) & 31 & 15.7 & 13 & 360 & 6.0 \\
\hline Mine water (used in this study) & 40 & 14.5 & 12 & 353 & 5.2 \\
\hline Aggressive solution & 400 & 724 & 600 & 8182 & 1.3 \\
\hline
\end{tabular}

$\mathrm{Mg}$ : magnesium; $\mathrm{Na}$ : sodium; $\mathrm{Cl}$ : chlorine; $\mathrm{SO}_{4}$ : sulfate.

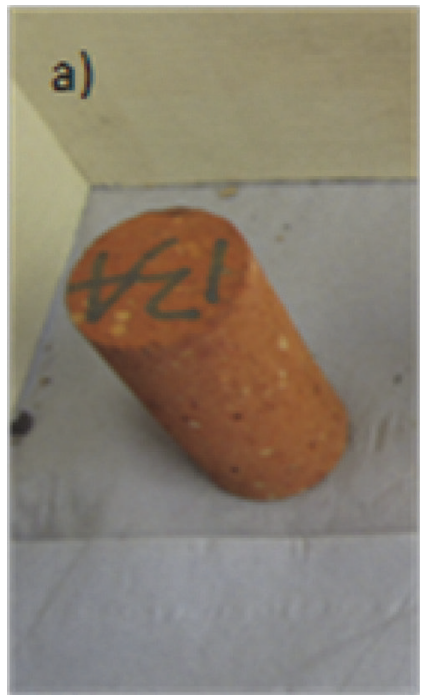

(a)

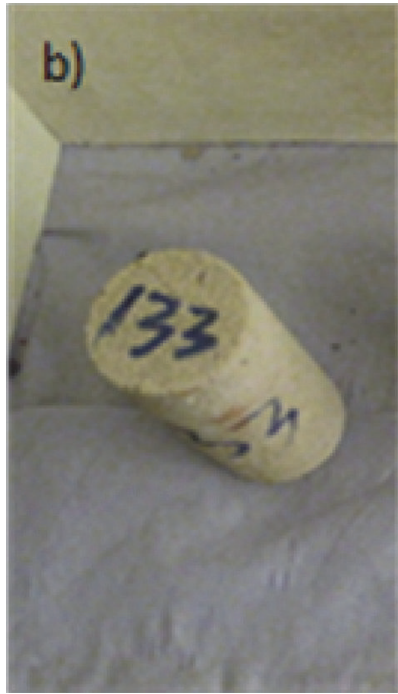

(b)

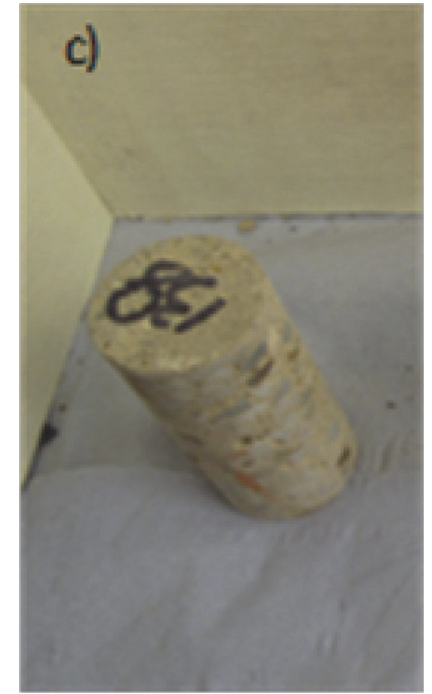

(c)

FIgURE 1: Test material: (a) brick, (b) mortar, and (c) concrete.

baseline test, followed by Phases 1 to 3 at 16-week intervals), as illustrated in Table 2.

Mass loss was calculated at each phase for each material. Mass loss is the most traditional parameter to measure the degree of deterioration on experimentally weathered material samples. In this study, all the cylinder samples were prepared, cured (for mortar and concrete), oven-dried at $50^{\circ} \mathrm{C}$ for 24 hours, marked, and weighed before placement within the immersion baths. At each phase, the selected samples were rinsed with tap water to remove loose reaction products and placed into an oven at $50^{\circ} \mathrm{C}$ for 24 hours before weighing. For each sample, the mass loss at each phase was calculated as

$$
\mathrm{ML}_{p}=\frac{\left(M_{i}-M_{p}\right)}{M_{i}} \times 100,
$$

where $M_{p}$ is mass at a given test phase and $M_{i}$ is initial mass before weathering. At each phase, at least 5 samples from each solution were measured and the average results of mass loss were calculated.

Uniaxial compressive strength (UCS) and triaxial tests were conducted at each phase to determine strength and stiffness parameters and thereby quantitatively assess the effect of weathering on the mechanical properties of the samples. The UCS test measures the stiffness (Young's modulus, E) and compressive strength $\left(\sigma_{c}\right)$ of test specimens. The tests were completed using the University of Nottingham 100-ton capacity stiff press under displacement control conditions at a rate of $0.02 \mathrm{~mm} / \mathrm{min}$. The applied load was measured by a load cell and vertical deformation of the samples was measured using two linear variable differential transformers (LVDTs) mounted adjacent to the sample. The average results from the two LVDTs were used to calculate axial strain. Four to five samples were tested for each material from each immersion bath at every test phase (a total of 135 samples were prepared for UCS testing). The test procedure followed the International Society for Rock Mechanics: testing measure [22].

Triaxial tests were conducted using a Hoek cell [23] and the same loading apparatus as for the UCS tests. Three confining pressures were applied to different samples of the same material at each test phase. Similar to the UCS tests, vertical (axial) load was applied to the samples under displacement control conditions at a fixed rate $0.02 \mathrm{~mm} / \mathrm{min}$. The applied load was measured by a load cell and the axial deformation of the samples was measured by two LVDTs. For each material, at each confining stress, 3 samples were tested (a total of 243 samples were prepared for the triaxial testing). The tests were conducted following the International Society for Rock Mechanics: Testing Methods [22]. The Mohr-Coulomb failure criterion was used to define the shear strength of the lining materials in this study, providing the material friction angle, $\phi$, and cohesion intercept, $c$. 
TABLE 2: Lab test programme for determining weathering effects on the test material.

\begin{tabular}{lcccc}
\hline & Phase 0 & Phase 1 & Phase 2 & Phase 3 \\
& Baseline & 16 weeks & 32 weeks & 48 weeks \\
\hline Air & UCS/triaxial & & & UCS/triaxial \\
Potable water & & UCS/triaxial & UCS/triaxial & UCS/triaxial \\
Mine water & & UCS/triaxial & UCS/triaxial & UCS/triaxial \\
Aggressive solution & & UCS/triaxial & &
\end{tabular}

\section{Results and Discussion}

The experimental results are presented and discussed in this section. Due to the practicality of preparing a large number of samples, those in potable water were not tested at Phase 2 for all three materials. The mortar samples within the aggressive solution suffered considerable degradation after 48 weeks and could not be tested. The strength of these samples was effectively reduced to zero. Therefore, no experimental data is given for mortar in the aggressive solution at Phase 3.

3.1. Mass Loss. Figure 2 presents the mass loss (1) experienced by the samples during the testing phases. It can be seen that all solutions had an initial effect (Phase 1 to 2) on the brick samples, with mass loss being greatest for the aggressive solution. From Phase 1 to 3 (32 weeks), the mass loss of the brick in the potable and mine water showed only a small variation, whereas the mass loss in the aggressive solution continued to increase. However, the initial water effect on mortar and concrete is much less obvious than for brick. The reason for this could be that the mortar and concrete had been immersed in water for 28 days during the preparation process and therefore the initial water effect is not clear.

Figures 2(b) and 2(c) show that the potable and mine water solutions had little effect on the mortar and concrete samples throughout the entire duration of the test (less than $3 \%$ mass loss after 48 weeks). The mortar and concrete samples in the aggressive solution show continued mass loss with time (no data point for mortar at 48 weeks due to complete sample deterioration). The trends of variation of the mass loss with time for the three materials are similar in the aggressive solution: the rate of mass loss is high from Phase 0 to 1 (8.3\% for brick, $7.2 \%$ for mortar, and $2.9 \%$ for concrete), stabilises somewhat from Phase 1 to 2 ( $1 \%$ for brick, $2.3 \%$ for mortar, and $1.3 \%$ for concrete), and then increases again from Phase 2 to 3 (3.2\% for brick, $4 \%$ for concrete). The increased rate of mass loss from Phase 2 to 3 illustrates that the combined effects of time and acid are important.

3.2. UCS Tests. The stress-strain relationships of the brick, mortar, and concrete samples from the UCS tests are shown in Figures 3, 4, and 5, respectively. The data from brick samples in Figure 3 do not show a clear trend when comparing Phase 0 through to Phase 3 for any of the immersion conditions. The samples showed considerable variability in results at any given stage of testing (due to the variability of brick composition and build quality) and therefore it is difficult to distinguish any weathering effects on the samples.
Figure 4(a) shows that the potable water had a minor effect on the stiffness (given by the slope of the curves within the initial linear range) and strength (maximum stress recorded) of the mortar. The mortar immersed in mine water (Figure 4(b)) did not show a significant change in stiffness from Phase 0 to 2; however, a reduction in stiffness is noted at Phase 3. Figure 4(c) shows that the stiffness of the mortar in the aggressive solution decreased immediately with time up to Phase 2. The deterioration of the physical properties of the mortar is much clearer for the highly acidic aggressive solution. At the onset of loading, the stiffness is noted to be very small (given by a shallow line in the stress-strain data). This is likely due to the fact that the acid attack opens microcracks at the exposed surface of the samples, making the outer regions of the samples much weaker and resulting in lower overall stiffness. The inner, less weathered regions of the cores eventually have the effect of increasing the stiffness of the samples during testing. The overall effect of the varying degree of weathering is a bilinear stiffness relationship. In Figure 4(c), Phase 3 results for the mortar in the aggressive solution are not given because the material was deteriorated to a state that could not be tested. The strength and stiffness of the mortar at this stage had effectively reduced to zero.

The UCS test data on concrete samples in Figure 5 shows that the effect of mine water was negligible during the test period; however, the aggressive solution had a drastic influence on the stress-strain relationship. Unlike the mortar, the concrete underwent a relatively minor variation of stressstrain behaviour from Phase 0 to 2 in the aggressive solution, which suggests the concrete was more capable of resisting the aggressive acidic attack, at least for a relatively short period of time. A dramatic reduction of stiffness and strength was measured from Phase 2 to 3 . The bilinear stiffness relationship is also found for concrete samples after 48 -week immersion in the aggressive solution.

The data in Figures 3-5 were used to quantify the effect of weathering on the strength and stiffness of the samples, as presented in Table 3 (brick), Table 4 (mortar), and Table 5 (concrete). Uniaxial compressive strength was taken as the maximum value of stress obtained during a given test. Tangent Young's modulus was calculated as the slope of the stress-strain relationship in the linear zone from $45 \%$ to $55 \%$ of the uniaxial compressive strength. The secant modulus gives a measure of the overall or average stiffness behaviour of the materials up to failure and is defined as the ratio of stress to strain at the point of the maximum stress.

For the brick UCS test data (Table 3), taking into account the considerable variability of test results at a given phase of 


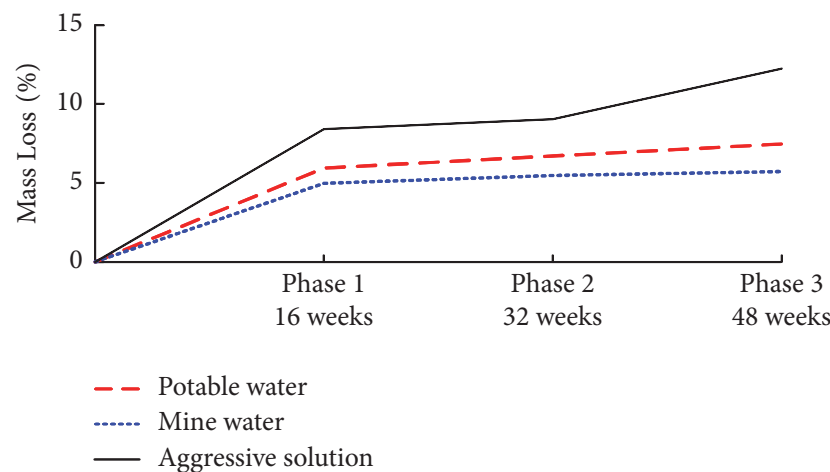

(a)

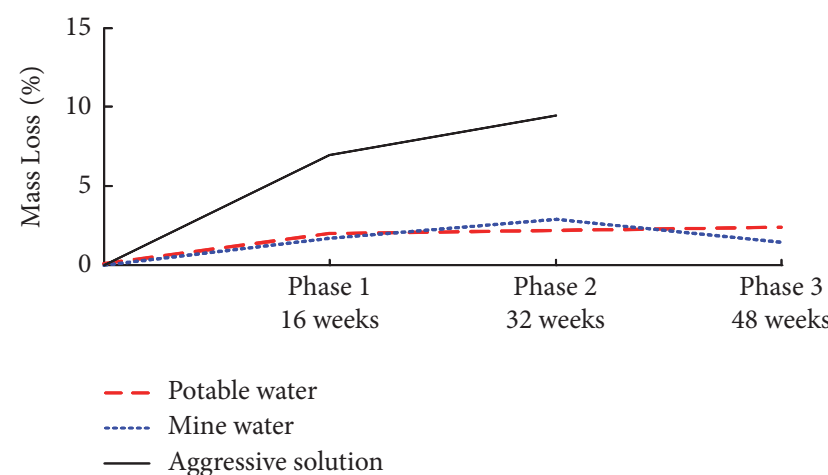

(b)

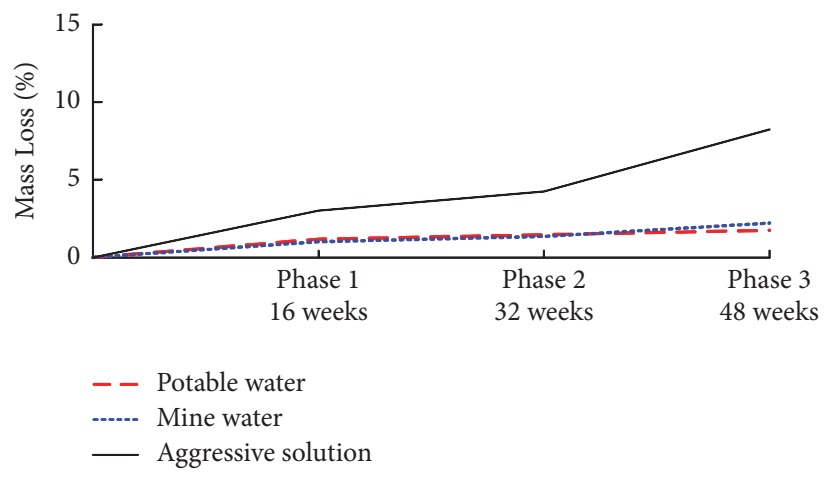

(c)

Figure 2: Mass loss of (a) brick, (b) mortar, and (c) concrete.

TABLE 3: Brick: compressive strength, tangent modulus, and secant modulus.

\begin{tabular}{|c|c|c|c|}
\hline \multirow[b]{2}{*}{ Phase } & \multicolumn{3}{|c|}{ Solutions } \\
\hline & $\begin{array}{c}\text { Potable } \\
\text { water }\end{array}$ & $\begin{array}{l}\text { Mine } \\
\text { water }\end{array}$ & $\begin{array}{c}\text { Aggressive } \\
\text { solution }\end{array}$ \\
\hline \multicolumn{4}{|c|}{ Compressive strength (MPa) } \\
\hline Phase 0 ( 0 weeks $)$ & 11.66 & 11.66 & 11.66 \\
\hline Phase 1 (16 weeks) & 9.16 & 12.38 & 12.18 \\
\hline Phase 2 (32 weeks) & - & 14.26 & 11.05 \\
\hline Phase 3 (48 weeks) & 12.08 & 15.52 & 13.54 \\
\hline \multicolumn{4}{|l|}{ Tangent modulus (GPa) } \\
\hline Phase 0 ( 0 weeks $)$ & 3.06 & 3.06 & 3.06 \\
\hline Phase 1 (16 weeks) & 2.72 & 2.38 & 2.93 \\
\hline Phase 2 (32 weeks) & - & 4.82 & 3.47 \\
\hline Phase 3 (48 weeks) & 3.51 & 6.16 & 3.15 \\
\hline \multicolumn{4}{|l|}{ Secant modulus (GPa) } \\
\hline Phase 0 ( 0 weeks $)$ & 2.28 & 2.28 & 2.28 \\
\hline Phase 1 (16 weeks) & 1.81 & 2.03 & 2.36 \\
\hline Phase 2 (32 weeks) & - & 3.77 & 2.42 \\
\hline Phase 3 (48 weeks) & 2.92 & 4.91 & 2.45 \\
\hline
\end{tabular}

testing, there is no clear evidence of significant weathering taking place.
TABLE 4: Mortar: compressive strength, tangent modulus, and secant modulus.

\begin{tabular}{|c|c|c|c|}
\hline \multirow[b]{2}{*}{ Phase } & \multicolumn{3}{|c|}{ Solutions } \\
\hline & $\begin{array}{c}\text { Potable } \\
\text { water }\end{array}$ & $\begin{array}{l}\text { Mine } \\
\text { water }\end{array}$ & $\begin{array}{c}\text { Aggressive } \\
\text { solution }\end{array}$ \\
\hline \multicolumn{4}{|c|}{ Compressive strength $(\mathrm{MPa})$} \\
\hline Phase 0 ( 0 weeks $)$ & 10.19 & 10.19 & 10.19 \\
\hline Phase 1 (16 weeks) & 8.48 & 9.59 & 8.89 \\
\hline Phase 2 (32 weeks) & - & 12.42 & 7.17 \\
\hline Phase 3 ( 48 weeks) & 11.51 & 11.31 & - \\
\hline \multicolumn{4}{|l|}{ Tangent modulus (GPa) } \\
\hline Phase 0 ( 0 weeks $)$ & 4.85 & 4.85 & 4.85 \\
\hline Phase 1 (16 weeks) & 3.52 & 4.88 & 1.80 \\
\hline Phase 2 (32 weeks) & - & 4.73 & 1.00 \\
\hline Phase 3 ( 48 weeks) & 3.20 & 2.55 & - \\
\hline \multicolumn{4}{|l|}{ Secant modulus (GPa) } \\
\hline Phase 0 ( 0 weeks $)$ & 2.96 & 2.96 & 2.96 \\
\hline Phase 1 (16 weeks) & 2.45 & 3.31 & 1.33 \\
\hline Phase 2 (32 weeks) & - & 3.06 & 0.73 \\
\hline Phase 3 ( 48 weeks) & 1.61 & 1.74 & - \\
\hline
\end{tabular}

For the mortar samples, it can be seen that the compressive strength of mortar in potable and mine water showed little variation and increased slightly from Phase 1 to 3 due to 




(a)

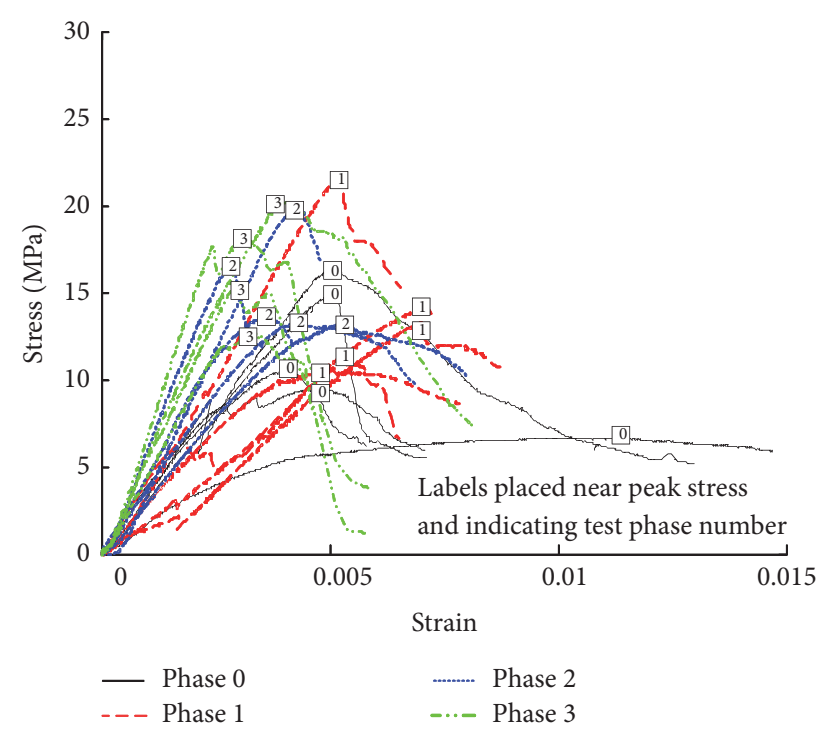

(b)

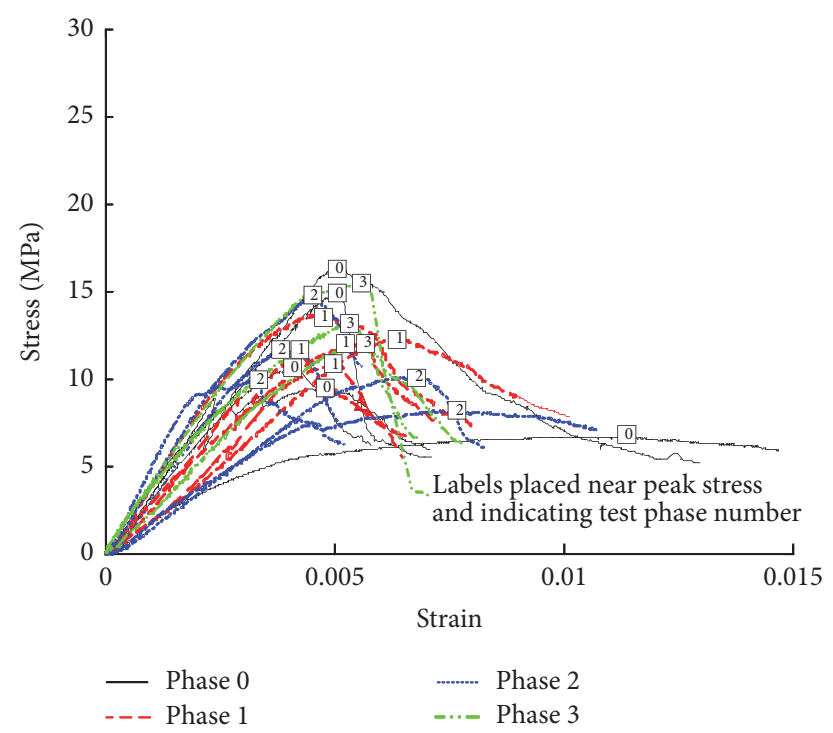

(c)

FIGURE 3: UCS of brick in (a) potable water, (b) mine water, and (c) aggressive solution.

the effect of curing. It is also noted that the tangent and secant modulus data from the mine water do not show a variation any greater than the data from the potable water. The aggressive solution had a pronounced effect on tangent modulus, secant modulus, and compressive strength of the mortar (Table 4). The initial effect of the aggressive solution on stiffness is considerable; from Phase 0 to Phase 1, tangent and secant modulus decreased by $63 \%$ and $55 \%$, respectively. The strength of mortar, however, only showed a slight decrease over the same period. The aggressive solution caused the material to soften but did not change its maximum strength. After a longer period of exposure in the aggressive solution, the strength and modulus effectively deteriorated to zero (the bulk of the mortar samples had been broken up). The results show that, for mortar over the tested time period, the stiffness was affected more significantly than compressive strength.

For concrete samples, potable and mine water had little effect on compressive strength and stiffness; a small variation is observed from Table 5 . The strength of concrete specimens also shows good resistance to acid attack over the initial stage of testing; only a slight variation of strength is observed between Phases 0 and 1 . However, after a relatively long immersion time (from Phase 1 to Phase 3 ) in the aggressive solution, the compressive strength of concrete was reduced by about 40\%. This result agrees with Bassuoni and Nehdi [24], who also conducted a series of compression tests to determine the percentage of strength loss of various concrete mixes 


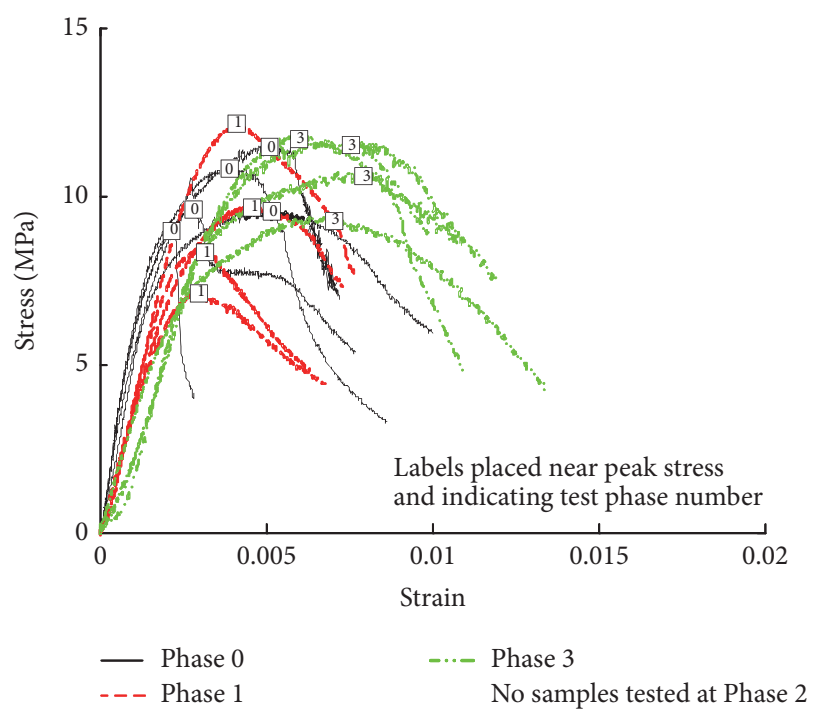

(a)

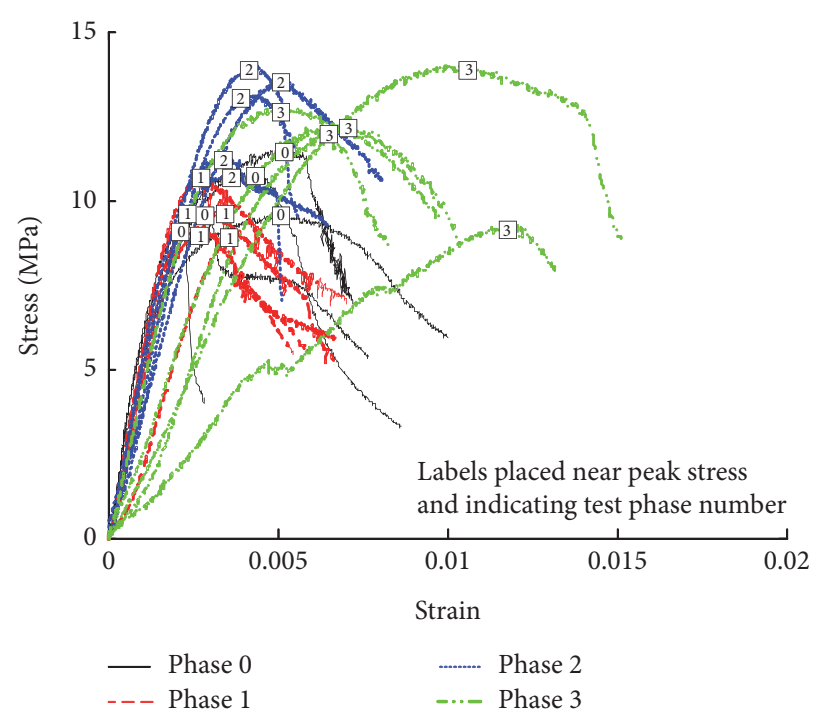

(b)

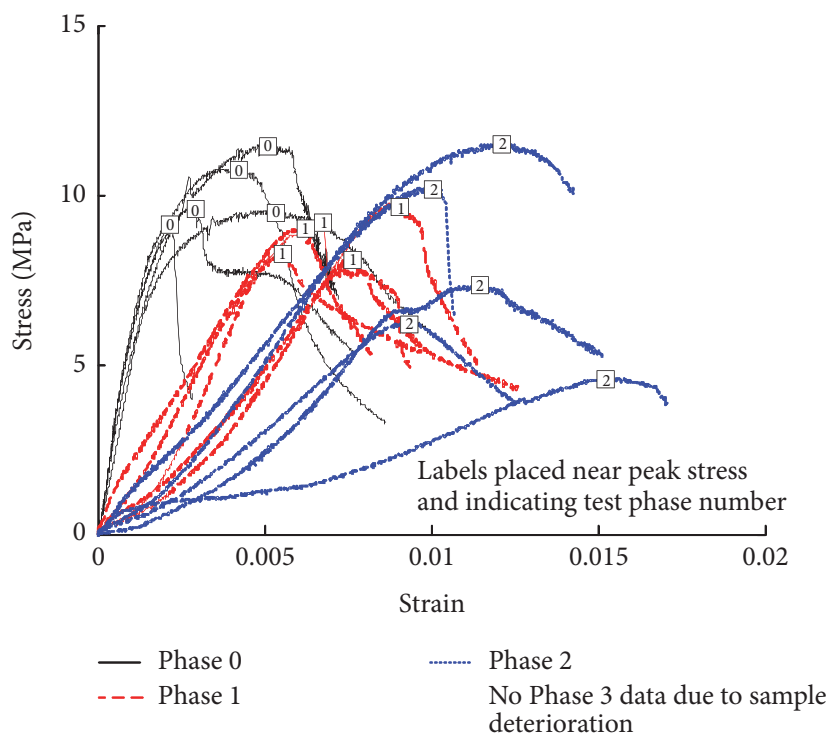

(c)

FIGURE 4: UCS of mortar in (a) potable water, (b) mine water, and (c) aggressive solution.

after long-term exposure to sulfuric acid attack. Their results showed that the maximum strength loss of the concrete samples was about $27 \%$. The effect of the aggressive solution on the stiffness of concrete is shown as an almost linear decrease of tangent and secant modulus from Phase 0 to 3. Similar to mortar, the results show that the stiffness of concrete is more sensitive to the harsh acid environment than the compressive strength.

3.3. Triaxial Tests. Typical plots of maximum axial stress against confining pressure from the triaxial tests on brick, mortar, and concrete (Phase 0) are shown in Figure 6. A linear strength envelope was obtained by fitting a line to the data points in each plot. With each gradient and intercept of the straight line, the internal friction angle and cohesion intercept of the material was calculated. Using the derived values of $c$ and $\phi$, the $\tau$ - $\sigma$ relationships for the lining materials were evaluated, as shown in Figure 7 (brick), Figure 8 (mortar), and Figure 9 (concrete).

According to the data in Figures 7-9, only a small variation of shear strength is observed for all samples in the potable and mine water even after 48 weeks. However, the shear strength of the materials was significantly affected by the aggressive solution. For brick samples (Figure $7(\mathrm{c})$ ), the shear strength at low confining stress is considerably reduced at Phase 3 in the aggressive solution. With an increase in confining stress, the degradation of shear strength is less significant. This is likely due to the effect of the confining pressure in the triaxial test which would tend to close microcracks within a sample which are caused by acid attack, therefore causing the weathering effects at high confining stress to be less obvious. 


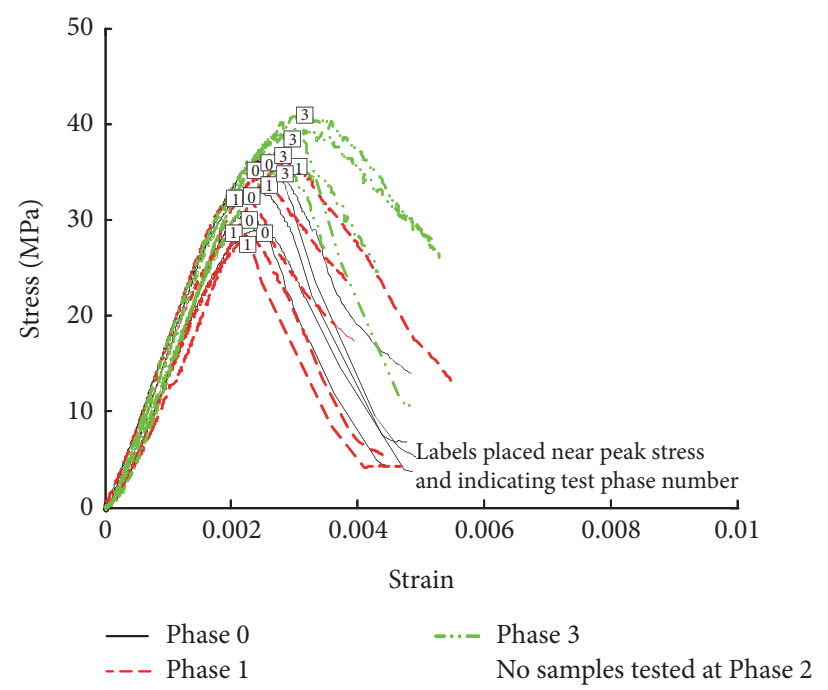

(a)

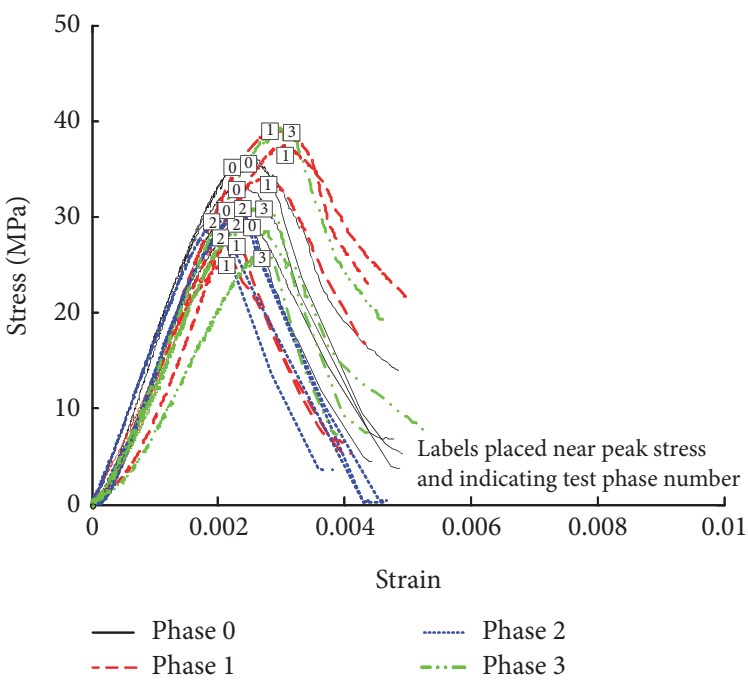

(b)

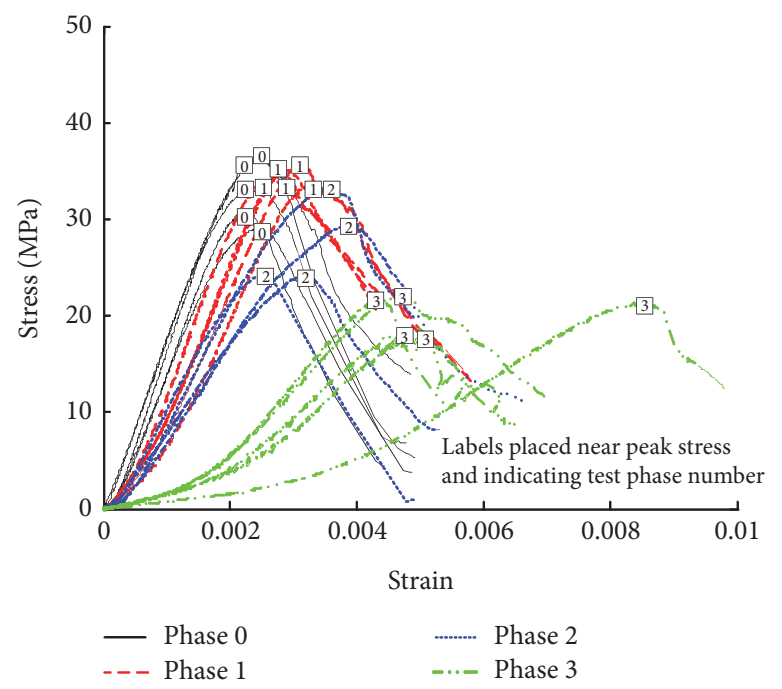

(c)

FIGURE 5: UCS of concrete in (a) potable water, (b) mine water, and (c) aggressive solution.

For mortar (Figure 8(c)), the aggressive solution did not have a significant effect on the shear strength from Phase 0 to Phase 2. However, complete degradation was observed at Phase 3, where near-complete disintegration of samples was observed. This result is different from the UCS test data which showed a continuous reduction of strength for mortar over the same period. This may also be due to the effect of the confining pressure on weathering induced microcracks.

For concrete in the aggressive solution (Figure 9(c)), a continuous decrease of strength from Phase 0 to Phase 3 was found. This is likely to be due to the fact that concrete is a stronger material compared to brick and mortar, and the proportion of the confining stress to the strength of the concrete is therefore less than for the other materials. The effect of the confining stress to close-up microcracks would therefore be less for the concrete compared to the other materials. It is also noted that the rate of strength degradation increases after Phase 2, indicating the importance of time on the weathering effects.

According to the results presented in this study, it was found that the decrease of compressive and shear strength has different trends compared to the mass loss data of the three materials under acid attack. Therefore, it may be inappropriate to evaluate the strength degradation of the materials from the mass loss data. This observation agrees with other findings that the variation of mass loss does not necessarily reflect the variation of mechanical properties [24]. In their study, Bassuoni and Nehdi [24] plotted the relationship between mass loss and compressive strength loss of concrete samples with different mixtures after 12 weeks of exposure to sulfuric acid solution. According to their results, they concluded that compressive strength loss did not have a direct relation with mass loss of concrete specimens under sulfuric acid attack. This observation has been reported by others as well $[25,26]$. 


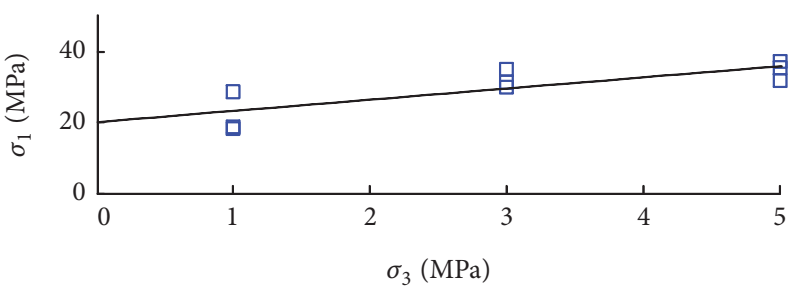

(a)

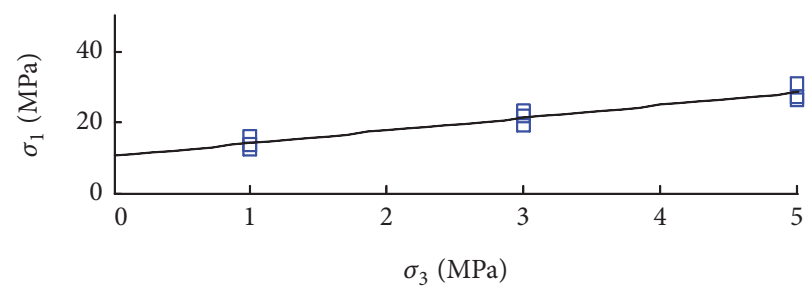

(b)

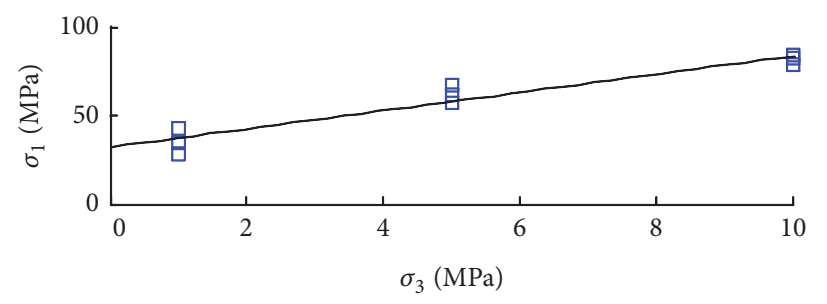

(c)

FIGURE 6: Maximum axial stress against confining stress for triaxial tests on (a) brick, (b) mortar, and (c) concrete at Phase 0.

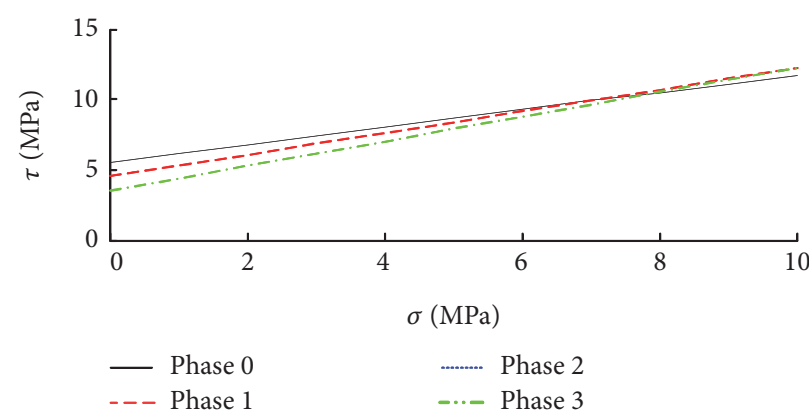

(a)

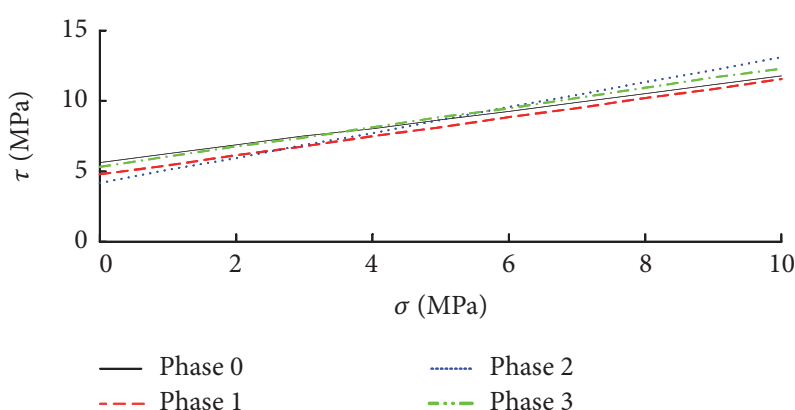

(b)

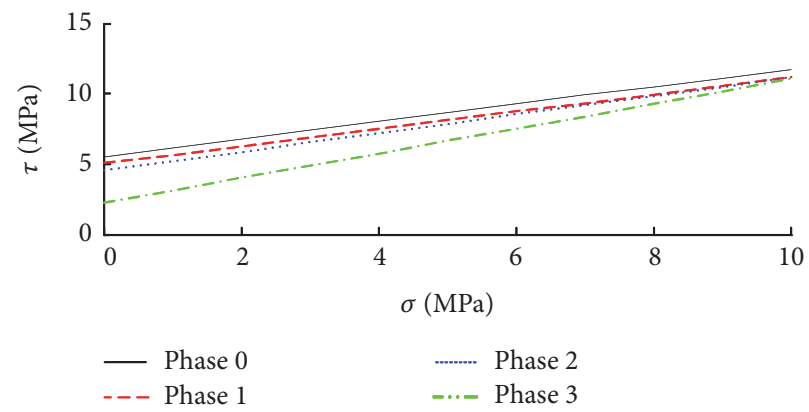

(c)

FIGURE 7: Shear strength envelope of brick in (a) potable water, (b) mine water, and (c) aggressive solution.

\section{Conclusions}

A programme of weathering tests was undertaken to examine the effect of harsh environmental conditions that are characteristic of flooded mine shafts on the mechanical properties of shaft lining materials, namely, brick, mortar, and concrete. Three different immersion solutions were used: potable water, representative mine water, and a more aggressive solution. Four phases of laboratory tests were conducted to assess the degradation of the mechanical properties of the materials. According to the test results, the following conclusions can be drawn:
For the samples in the aggressive solution, the data showed that, in terms of mass loss, all three materials were sensitive to acid attack. A similar trend of variation of mass loss with time was observed for all material samples in the aggressive solution.

The weathering process had a pronounced effect on the behaviour of the mortar and concrete. Based on UCS tests, variable degrees of weathering resulted in a bilinear trend of mortar stiffness during loading and an almost linear decrease of Young's modulus of the concrete during the weathering process. A 


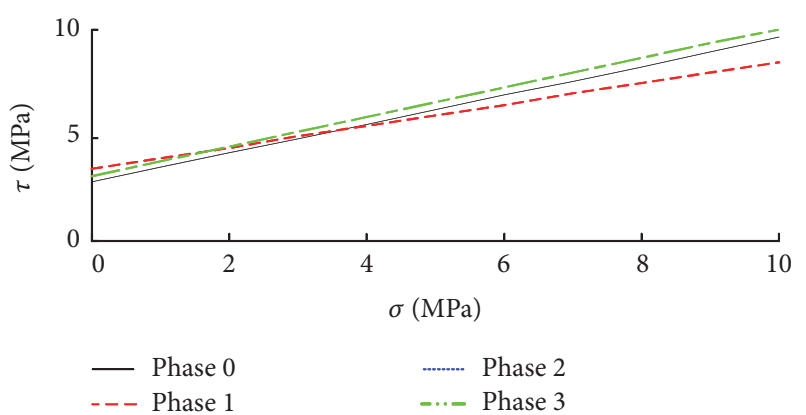

(a)

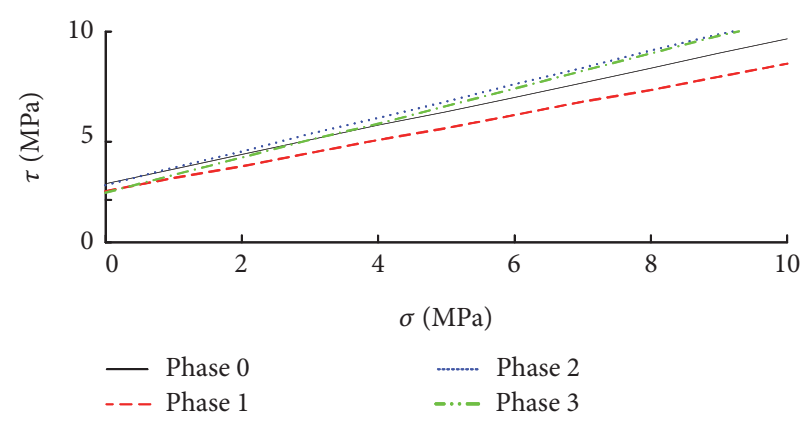

(b)

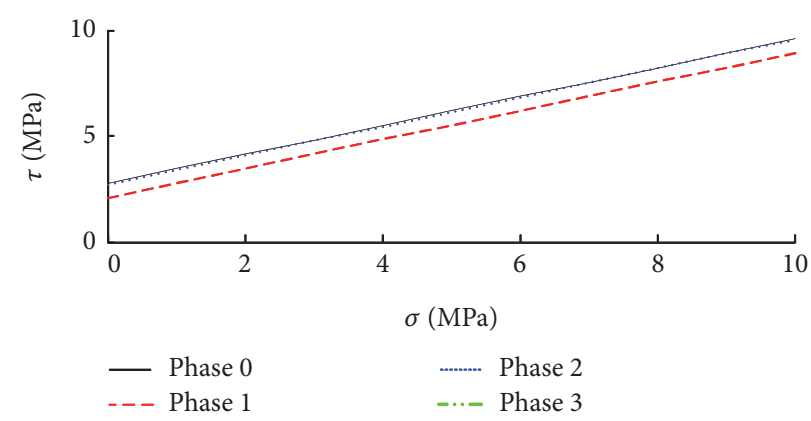

(c)

FIGURE 8: Shear strength envelope of mortar in (a) potable water, (b) mine water, and (c) aggressive solution.

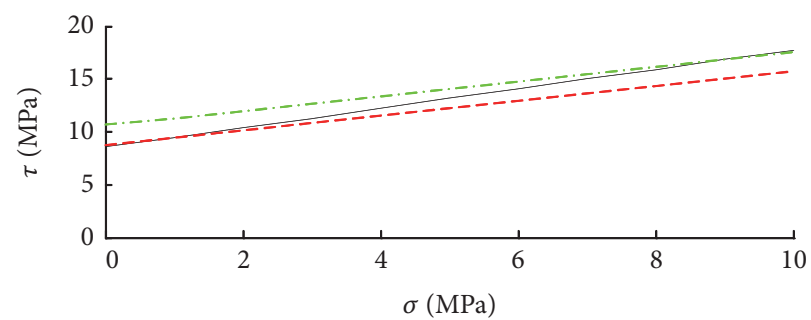

- Phase 0 - - - Phase 1
......... Phase 2

-..- Phase 3

(a)

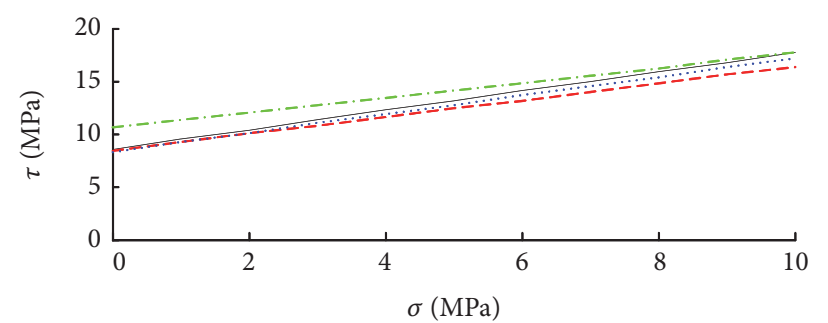

- Phase 0

- - - Phase 1

......... Phase 2

(b)

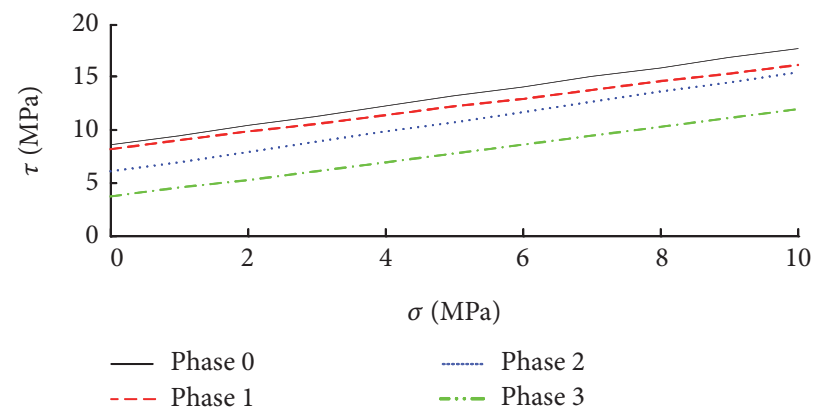

(c)

FIGURE 9: Shear strength envelope of concrete in (a) potable water, (b) mine water, and (c) aggressive solution. 
TABLE 5: Concrete: compressive strength, tangent modulus, and secant modulus.

\begin{tabular}{|c|c|c|c|}
\hline \multirow[b]{2}{*}{ Phase } & \multicolumn{3}{|c|}{ Solutions } \\
\hline & $\begin{array}{c}\text { Potable } \\
\text { water }\end{array}$ & $\begin{array}{l}\text { Mine } \\
\text { water }\end{array}$ & $\begin{array}{c}\text { Aggressive } \\
\text { solution }\end{array}$ \\
\hline \multicolumn{4}{|c|}{ Compressive strength (MPa) } \\
\hline Phase 0 ( 0 weeks $)$ & 33.67 & 33.67 & 33.67 \\
\hline Phase 1 (16 weeks) & 32.13 & 33.05 & 34.91 \\
\hline Phase 2 (32 weeks) & - & 32.13 & 26.31 \\
\hline Phase 3 (48 weeks) & 36.87 & 30.83 & 20.48 \\
\hline \multicolumn{4}{|l|}{ Tangent modulus (GPa) } \\
\hline Phase 0 ( 0 weeks $)$ & 18.67 & 18.67 & 18.67 \\
\hline Phase 1 (16 weeks) & 17.81 & 17.17 & 16.16 \\
\hline Phase 2 (32 weeks) & - & 18.31 & 11.12 \\
\hline Phase 3 (48 weeks) & 18.94 & 16.16 & 6.56 \\
\hline \multicolumn{4}{|l|}{ Secant modulus (GPa) } \\
\hline Phase 0 ( 0 weeks $)$ & 13.90 & 13.90 & 13.90 \\
\hline Phase 1 (16 weeks) & 13.77 & 12.60 & 11.86 \\
\hline Phase 2 (32 weeks) & - & 13.53 & 8.28 \\
\hline Phase 3 (48 weeks) & 13.26 & 11.73 & 3.95 \\
\hline
\end{tabular}

considerable decrease in the compressive strength of mortar and concrete samples was measured. The test results showed that Young's modulus was found to be more sensitive to acid attack compared to compressive strength for both materials. This suggests that large deformation may be observed within shaft linings before significant collapse occurs.

According to the triaxial results, the shear strength of the three materials was shown to be sensitive to the attack of the aggressive solution. After 48week immersion in the aggressive solution, the shear strength of brick was reduced by more than $50 \%$ at the lowest confining stress. Mortar and concrete showed different behaviour under the aggressive solution attack in the triaxial tests due to different effects of confining pressure on the materials. A sudden drop of shear strength of mortar was found, whereas the shear strength of concrete was shown to reduce gradually with time.

\section{Competing Interests}

The authors declare that they have no competing interests.

\section{Acknowledgments}

The authors would like to acknowledge the financial support provided by the European Commission Research Programme of the Research Fund for Coal and Steel (RFCS). The work described in this paper was undertaken as part of the "Mine Shafts: Improving Security and New Tools for the Evaluation of Risks" (MISSTER) project, Grant Agreement RFCR-CT2010-00014.

\section{References}

[1] P. R. Healy and J. M. Head, Construction over Abandoned Mine Workings: CIRIA, 1984.

[2] A. Lecomte, R. Salmon, W. Yang et al., "Case studies and analysis of mine shafts incidents in Europe," in Proceedings of the 3rd International Conference on Shaft Design and Construction (SDC '12), London, UK, 2012.

[3] Y. Rama Mohana Rao, "Design state of structural concrete for mine shaft lining," Indian Concrete Journal, vol. 62, no. 2, pp. 91-96, 1988.

[4] Y. D. Jia, R. Stace, and A. Williams, "Numerical modelling of shaft lining stability at deep mine," Mining Technology, vol. 122, no. 1, pp. 8-19, 2013.

[5] B. Méndez, D. H. Palencia, E. Botero, and M. P. Romo, "Numerical computation of shaft lining pressures in granular soil," in Proceedings of the 13th International Conference of the International Association for Computer Methods and Advances in Geomechanics (IACMAG '11), B. Méndez, D. H. Palencia, E. Botero, and M. P. Romo, Eds., Centre for Infrastructure Engineering and Safety, Melbourne, Australia, May 2011.

[6] Q. Yu, J. Ma, H. Shimada, and T. Sasaoka, "Influence of coal extraction operation on shaft lining stability in eastern Chinese coal mines," Geotechnical and Geological Engineering, vol. 32, no. 4, pp. 821-827, 2014.

[7] P. Lopez-Arce and J. Garcia-Guinea, "Weathering traces in ancient bricks from historic buildings," Building and Environment, vol. 40, no. 7, pp. 929-941, 2005.

[8] J. A. Larbi, "Microscopy applied to the diagnosis of the deterioration of brick masonry," Construction and Building Materials, vol. 18, no. 5, pp. 299-307, 2004.

[9] C. Gentilini, E. Franzoni, S. Bandini, and L. Nobile, "Effect of salt crystallisation on the shear behaviour of masonry walls: an experimental study," Construction and Building Materials, vol. 37, pp. 181-189, 2012.

[10] M. O'Farrell, S. Wild, and B. B. Sabir, "Resistance to chemical attack of ground brick-PC mortar: Part I. Sodium sulphate solution," Cement and Concrete Research, vol. 29, no. 11, pp. 17811790, 1999.

[11] V. Kucera and S. Fitz, "Direct and indirect air pollution effects on materials including cultural monuments," in Proceedings of the 5th International Conference on Acidic Deposition: Science \& Policy (ACID REIGN '95), V. Kucera and S. Fitz, Eds., Kluwer Academic, Goteborg, Sweden, June 1995.

[12] M. J. De La Torre Lopez and E. Sebastian Pardo, “The effect of urban pollution on construction materials: stone and brick," in Proceedings of the 8th International Congress on the Deterioration and Conservation of Stone, pp. 325-332, 1996.

[13] S. K. Roy, K. B. Poh, and D. O. Northwood, "Durability of concrete-accelerated carbonation and weathering studies," Building and Environment, vol. 34, no. 5, pp. 597-606, 1999.

[14] C.-T. Chen and C.-W. Ho, "Influence of cyclic humidity on carbonation of concrete," Journal of Materials in Civil Engineering, vol. 25, no. 12, pp. 1929-1935, 2013.

[15] N. I. Fattuhi and B. P. Hughes, "Ordinary portland cement mixes with selected admixtures subjected to sulfuric acid attack," ACI Materials Journal, vol. 85, no. 6, pp. 512-518, 1988. 
[16] S. Ehrich, L. Helard, R. Letourneux, J. Willocq, and E. Bock, "Biogenic and chemical sulfuric acid corrosion of mortars," Journal of Materials in Civil Engineering, vol. 11, no. 4, pp. 340344, 1999.

[17] PREdiction and Monitoring of SubSIDENCE Hazards above Coal Mines Technical Project report, Supported by Research Fund for Coal and Steel, RFCR-CT-2007-00004.

[18] British Standard, "EN 771-1: Specification for clay masonry unit," 2011.

[19] British Standard, "PD 6678: Guide to the specification of masonry mortar," 2005.

[20] British Standard, "EN 197-1: Cement composition, specifications and conformity criteria for common cements," 2011.

[21] D. K. Nordstrom, C. N. Alpers, C. J. Ptacek, and D. W. Blowes, "Negative $\mathrm{pH}$ and extremely acidic mine waters from Iron Mountain, California," Environmental Science and Technology, vol. 34, no. 2, pp. 254-258, 2000.

[22] "The International Society for Rock Mechanics: testing measure," 1985.

[23] P. V. Lade, Triaxial Testing of Soils, John Wiley \& Sons, 2016.

[24] M. T. Bassuoni and M. L. Nehdi, "Resistance of self-consolidating concrete to sulfuric acid attack with consecutive $\mathrm{pH}$ reduction," Cement and Concrete Research, vol. 37, no. 7, pp. 10701084, 2007.

[25] N. I. Fattuhi and B. P. Hughes, "The performance of cement paste and concrete subjected to sulphuric acid attack," Cement and Concrete Research, vol. 18, no. 4, pp. 545-553, 1988.

[26] ASTM, "Chemical resistance of mortars, grouts, and monolithic surfacings and polymer concretes," in Annual Book of American Society for Testing Materials, vol. 4.05, pp. 130-135, ASTM, Philadelphia, Pa, USA, 1997, ASTM C 267. 

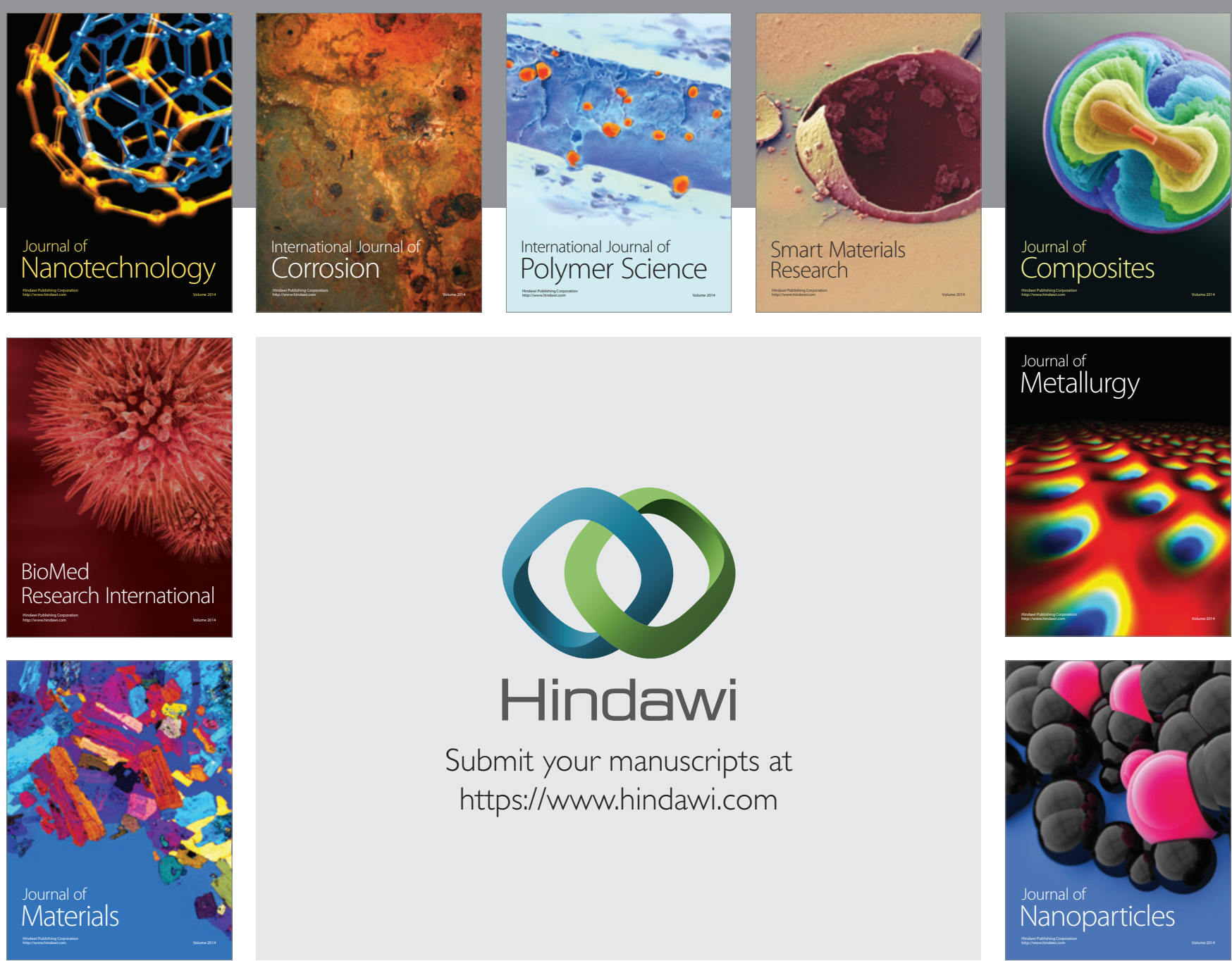

\section{Hindawi}

Submit your manuscripts at

https://www.hindawi.com

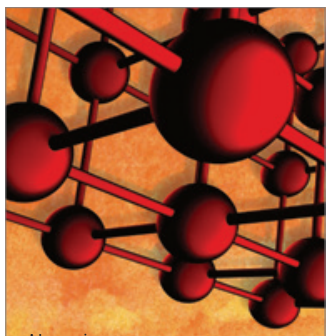

Materials Science and Engineering
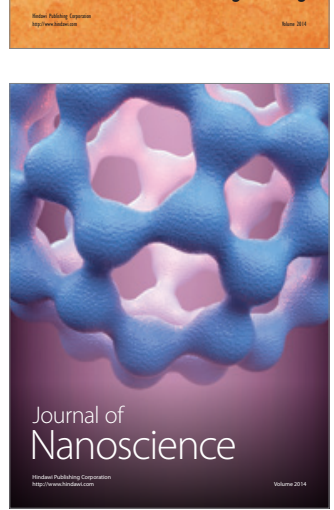
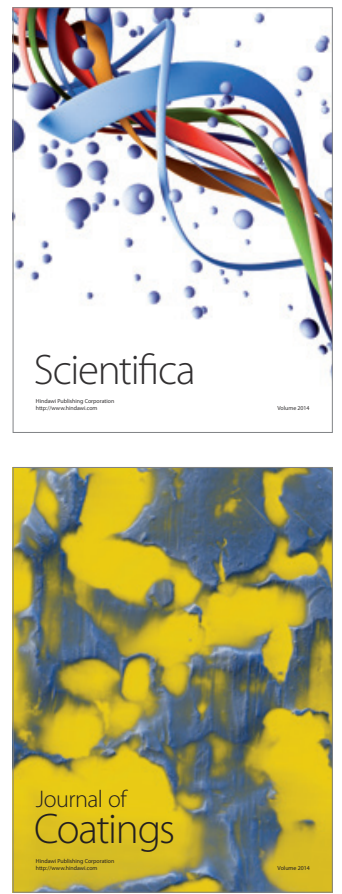
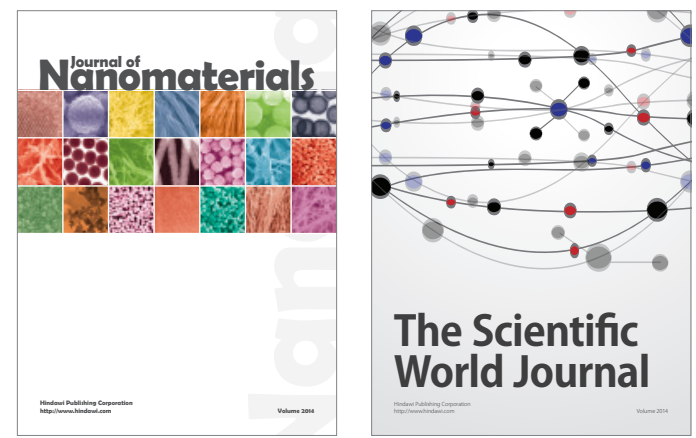

The Scientific World Journal
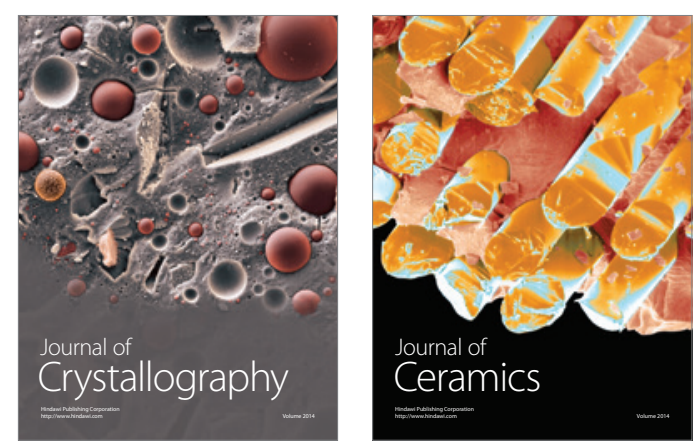
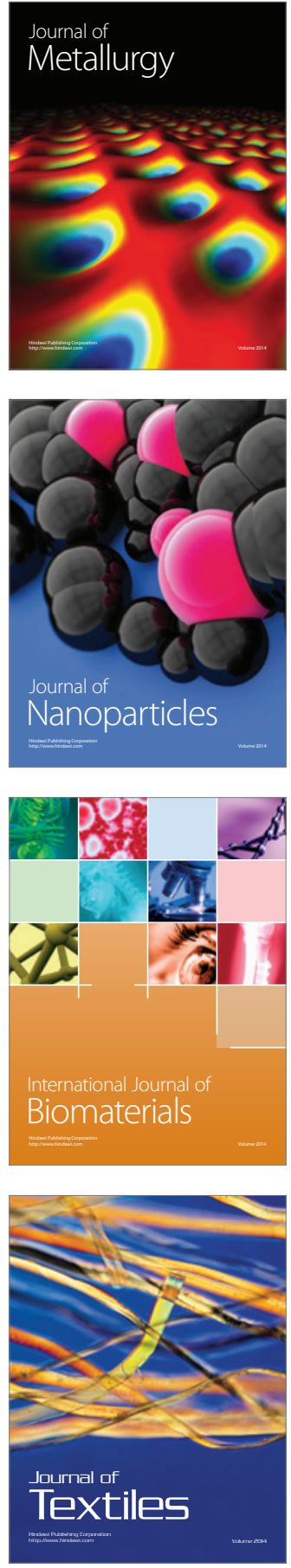